Journal of the Scholarship of Teaching and Learning, Vol. 20, No. 3, December 2020, pp. 81- 96. doi: 10.14434/josotl.v20i3.26920

\title{
Reflecting on a Multi-Perspective Approach to Teaching and Learning about Police Shootings
}

\author{
Joseph Alexander Ferrandino \\ Ferris State University \\ jferrand@,ferris.edu
}

\begin{abstract}
This reflective essay highlights the importance of project structure when teaching highly controversial topics. I review research that shows differing approaches to teaching highly controversial subjects and the impact of the approaches on learning outcomes. I then reflect on the outcomes of deploying a non-directive, peacekeeping approach to address the issue of police-involved shootings in a criminal justice class. Finally, I draw attention to ancillary issues that emerge in this project structure as well as how the results impacted my own thinking about this topic.
\end{abstract}

\section{Introduction}

In this essay, I reflect on the pedagogy I created to teach students about a controversial social topicofficer-involved shootings - and more importantly, what I learned from the process and the students' work as a result. By the spring of 2017, police officer-involved shootings were a prominent social issue, reignited by the 2014 shooting death of Michael Brown in Ferguson, Missouri, spurring the Black Lives Matter movement. This was met with the counter-narrative Blue Lives Matter movement, cementing two contrasting viewpoints which seemed in stark contrast to another — two coins — rather than two sides of the same co-existing coin. Teaching such a controversial topic in a capstone criminal justice course that contained officers as well as students critical of the criminal justice system is known to be tricky (see Payne \& Gainey, 2000). Thus, it was essential to create a teaching and learning process as objective and data-driven as possible given the controversial nature of the topic, the student makeup in the class, and the outcomes of the course itself. This work starts and ends with an assessment of that process and how it was structured.

In the middle part of this essay, I look not solely at what over fifty students learned from their multiple semester, multiple perspective, and collaborative research process but on what they taught me about police officer-involved shootings and controversial topics as a result. While the pedagogy was designed to teach students, it is perhaps I who learned more from them, a twist on the "protégé effect" in which they learn more about a topic from teaching other students. It is here where I believe this essay has the most value for professors reading it relative to teaching about controversial issues. I conclude with a critique of the process I created, including its mistakes, benefits, challenges and potential for teaching and learning about other controversial topics that transverse one specific course, discipline or field.

\section{Teaching Controversial Topics and the Issue of Perspective}

There are few more seemingly controversial topics in the criminal justice classroom over the past several years than officer-involved shootings, and these discussions are happening around campus in other disciplines as well. Teaching based on controversial topics also connects to the issue of student perspective taking contrasted with perspective getting, the role of the instructor in the process and the philosophical foundations of what constitutes a controversial issue relative to how it can, or could, be taught. I started building this pedagogical approach by learning about teaching controversial issues, which is what I believed officer-involved shootings to be. 
Payne and Gainey (2000) laid out five pathways professors could use in teaching controversial issues through discussions, focusing on the criminal justice classroom: the due process approach (equal amount of attention to both sides of the issue), the peacemaking approach (peace without resolving the conflict), the academic controversy approach (reaching agreement on differences), the devil's advocate approach (challenging student beliefs to spur discussion) and the avoidance approach (avoiding the discussion for any reason). Professors themselves fill one of three roles in these pathways: mentor, facilitator or arbiter. The goal of each approach and role is to have the most robust discussion of these issues in class with the least amount of problems normally associated with controversial topics where students and professors have strong and often differing opinions.

Other research at the secondary level has labeled the approaches to teaching controversial issues as: denial, where the teacher decides the issue is not really a controversial issue; privilege, where teacher has the answer and teaches to that perspective; avoidance, where the teacher is uncomfortable discussing it, so doesn't; or balance, where the matter is taught as a genuine issue from a balanced perspective and given a fair hearing (Hess, 2004). Hand (2008) differentiated between teaching-assettled (directive) and teaching-as-controversial (non-directive). The former is defined as "a problem taught along with its solution, a question along with its answer; the intended outcome is precisely that students should come to share the teacher's view on a matter" (p. 213) while the latter is conceptualized as:

Presenting as a matter on which different views are or could be held and to expound those different views as impartially as possible. It is to acknowledge and explore various possible answers to a question without endorsing any of them. The intended outcome of such teaching is, at least, that students should understand a range of views on a topic and the arguments in their support, and, at most, that they should hold and be able to defend considered views of their own; it is emphatically not that they should come to share the view favored by the teacher (p. 213).

The non-directive approach is similar to the due process (Payne \& Gainey, 2000) and balanced approach (Hess, 2004) in that the issue can be seen in several ways, with each side having some validity. Hand (2008) further discusses two criteria that require teaching-as-controversial: the epistemic criterion, where contrary views on a topic can be held without these views being contrary to reason, and the political criterion, where there is a distinction between public and private values. The topic of officer-involved shootings aligns with teaching-as-controversial, requiring non-directive teaching, and clearly represents a wide distinction within and between public and private values though contrary views could reasonably be held, meeting both of Hand's criterion.

Patenaude (2001) discussed teaching about emotive issues — in his case the death penaltyobjectively and with the goal of improving critical thinking rather than changing minds or opinions. He also supported using a balanced pedagogical stance, reflective of the due process approach (Payne \& Gainey, 2000), which included balanced coverage of all sides of the argument. Focusing on teaching about same sex marriage, Hand (2013) informs of framing (similar to perspective) and warns of steering, or "guiding participants, by means of strategic prompts, questions, and interjections, toward a predetermined conclusion" (p. 499), which is similar to Hess' privileged approach which can lead to charges of indoctrination and teaching the concept as settled (Hand, 2008). Despite these concerns, some propose that teachers should be able to endorse positions while teaching controversial issues, requiring a more directive teaching approach (Warnick \& Smith, 2014; Yacek, 2018). The study of officer-involved shootings seemed to me more controversial than settled and as such was more suited to a non-directive (balanced) than directive (guided and/or endorsed) approach as the circumstances,

Journal of the Scholarship of Teaching and Learning, Vol. 20, No. 3, December 2020. josotl.indiana.edu 
nuances and context of each shooting are important as opposed to two general sides to take on an issue (i.e. the side of the police or the side of the citizen).

Hand (2013) presents three frames in discussing controversial issues in the classroom: the perfectionist frame, the antiperfectionist frame and the practical accommodation frame. The latter frame "gives center stage to an altogether different aim: that of negotiating a compromise position acceptable to discussants with conflicting views on same-sex marriage. Rather than trying to find the right public policy on same-sex marriage, participants in the discussion seek the policy that best accommodates their diverse moral views and conceptions of the good" (p. 507). This frame is consistent with the peacemaking approach (Payne \& Gainey, 2000) and can be done through guiding rather than endorsing when teaching about controversial issues (Gregory, 2014). Some element of this approach would be necessary in teaching about officer-involved shootings. Police officers have a monopoly on the use of force in American society (Bittner, 1970) and the use of deadly force, if properly utilized and applied, is a necessity of the job. However, not all officer-involved shootings are justified or within policy, and some accommodation is needed in the social and legal response to those incidents. The nuances of each incident are important rather than viewing all officer-involved shootings with the same lens or trying to support a side rather than seeing all sides, i.e. getting rather than taking perspective.

Ferguson and Musheno (2000) informed of the value of using stories to teach about injustice to have students see both sides of an event, or engage in perspective taking, rather than telling students what judgements should be made. The authors define perspective taking as "seeing one's judgement in relationship to others" (p. 151) and structured their pedagogy around putting students in other people's shoes in order to better prepare them for community-policing. Similar conceptually to a balanced approach, this definition does not include the student getting perspective in order to see the topic in relationship to the perspective of others. As argued by Epley (2014), we are far more accurate when we get perspective from people rather than try to guess their perspective. Though we are unable to get the perspective from people directly involved in police shootings, students can get perspective through examination of data and cases on the issue across the spectrum of events that impact citizens, police and the communities they serve.

Once I learned how I should structure the teaching on this controversial issue-non-directed, balanced/due process, framed with practical accommodation and focused on students getting rather taking perspective-I turned to the existing data sources I could use as content to achieve those goals. What I learned while reviewing that data led me to create my own pedagogical approach to teach this topic, and I focus on that process for the rest of the essay.

\section{Existing Data Sources of Officer-Involved Shootings}

Students need objective and complete sources of data in order to get perspective on any controversial issue such as police-involved shootings, but it is not available in one place. Klinger (2012) noted two major problems with existing attempts to maintain national databases on police shootings: inaccuracy and a singular focus on fatal encounters. Both of these issues still persist today. However, another major issue emerged that made teaching this topic objectively very tough: the fragmentation of the data sources themselves. In reviewing the data sources, it became clear that each source only presented a singular perspective-either the police or the citizen-but not both concurrently, making all the existing data inherently biased. Each also had its own methods of data collection, operationalization, focus, and way of sharing its data. All had some value independently but not as a whole coherent picture I was seeking for students. I briefly summarize those data sources as well as how this data review was used to create a new data collection approach to create a new database that addressed all the limitations found (see Table 1 below).

Journal of the Scholarship of Teaching and Learning, Vol. 20, No. 3, December 2020. josotl.indiana.edu 
Two data sources detailed every incident in which a police officer was killed by a citizen. The first data source is the annual FBI UCR Law Enforcement Officers Killed and Assaulted Annual Report (FBI, 1994 - 2015) which is produced annually through a sampling of police departments across the country. The data gives a nearly full accounting of every officer killed each year by the reporting agency. The data is largely oriented to the officer but includes some information about suspects who killed police officers. The LEOKA report also contains valuable micro-level information about each officer death in the form of qualitative case studies that provide context about the incidents to balance the statistical data. The second long-term dataset from the police perspective is the Officer Down Memorial Page. Though not a traditional academic database, the Officer Down Memorial Page website (ODMP, n.d.) is a great source of information about officers killed in the line of duty. This source is highly accurate, and though one-sided and designed for a more far-reaching purpose than to document incidents, it does offer information about officers killed in the line of duty to get perspective. Both sources lack any data or information on non-fatal shootings of officers and neither includes any information on citizens shot and/or killed by police, limiting their objective value in teaching this controversial topic in accordance with the literature.

In recent years, data has been made available on the number of citizens shot and/or killed by police in the United States. The methods of these datasets vary, as do their focus and definitions. One of the more influential datasets has been the Washington Post Citizens Killed by Police Dataset (Washington Post, n.d.). Following the events in Ferguson, Missouri in 2014, several reporters at the Washington Post started tracking every fatal shooting in the United States by a police officer from January 1, 2015 to present (see Tate, Jenkins, Rich, Muyskens, Elliott, Mellnick \& Williams, 2016). The database is rich and permits multiple areas of quantitative inquiry relative to this population, including race, gender, age, whether the citizen was armed and if so with what weapon, had a history of mental illness or acted with aggression and whether a body camera caught the incident. The dataset is highly informative and reliable as well as being high in validity and accuracy. Several peer-reviewed articles have used and/or cited the Washington Post dataset in studying fatal officer-involved shootings where citizens are killed (see Nix, Campbell, Byers \& Alpert, 2017; Shane, Lawton \& Swenson, 2017; Alpert, 2016), further evidence of its value. The Washington Post data omits nonfatal shootings and officers shot and/or killed and while it collects data on the police officers involved it does not make that information public. Thus, the dataset is useful to supplement the data on officers killed and assaulted but does not provide wider context and perspective if used in isolation. It does however permit students to gain perspective of the citizen side of this topic.

A multitude of other internet sources were also reviewed that detail citizens shot and/or killed by police, including but not limited to: Killedbypolice.net (a website that uses aggregated Facebook and internet "scrapings" to create a list of every citizen killed by police in the US starting in 2014); Fatalencounters.org (a website created by a former newspaper editor to document all the missing context in officer-involved homicides across the United States; site only focuses on fatal incidents); The Gun Violence Archive (a non-profit organization that runs a website with a mission to create "an online archive of gun violence incidents collected from over 2,500 media, law enforcement, government and commercial sources daily in an effort to provide near-real time data about the results of gun violence); and Mappingpoliceviolence.org (an aggregating website that uses two of the above sources and social media to make a database of fatal police shootings).

A final and emerging yet limited source of data on officer-involved shootings comes from the field of critical data studies. This field views data as existing within power structures and rhetoric and taking on meaning and value that is defined by its owner, who controls the process from collection to dissemination, a perspective that has been applied to police shootings (Currie, Paris, Pasquetto \& Pierre, 2016). Currie and colleagues challenged the official statistics on police officer-involved homicides in Los Angeles County and held a counter-data action hackathon with citizen groups to

Journal of the Scholarship of Teaching and Learning, Vol. 20, No. 3, December 2020. josotl.indiana.edu 
examine and re-interpret the data. This approach is qualitative and does not involve primary data collection but does involve validating the data, much of which was found to contain discrepancies across datasets. Still, it shows that social interest groups can get perspective on the issue of policeinvolved shootings beyond official data, which is often lacking.

All of these databases, in isolation, lacked some important information to see the entire context of fatal and non-fatal police shootings from both perspectives - the officer and the citizenthough each also provided valuable information as a part of the whole. This review of the existing data sources in conjunction with the literature on teaching controversial issues led me to develop a new way for students to get both perspectives while creating their own database to learn from. It is that pedagogy to which I now turn. 
Table 1: Existing Officer-Involved Shooting Data Sources and Limitations

\begin{tabular}{|c|c|c|c|}
\hline Source & Focus & Data & Limitations \\
\hline $\begin{array}{l}\text { FBI, LEOKA Annual } \\
\text { Report }\end{array}$ & $\begin{array}{l}\text { Officers Killed in the Line } \\
\text { of Duty }\end{array}$ & $\begin{array}{l}\text { Quantitative and } \\
\text { Qualitative; summaries of } \\
\text { each incident }\end{array}$ & $\begin{array}{l}\text { No non-fatal shootings of officers included; no information about citizens shot } \\
\text { and/or killed by police; data lags about a year and a half }\end{array}$ \\
\hline $\begin{array}{l}\text { Officer Down Memorial } \\
\text { Page }\end{array}$ & $\begin{array}{l}\text { Officers Killed in the Line } \\
\text { of Duty }\end{array}$ & $\begin{array}{l}\text { Qualitative summaries of } \\
\text { the events and the officer }\end{array}$ & No non-fatal or citizen data; no quantitative context of all events nationally \\
\hline $\begin{array}{l}\text { Washington Post Police } \\
\text { Shooting Database }\end{array}$ & Citizens killed by police & $\begin{array}{l}\text { Quantitative and } \\
\text { categorical of all citizens } \\
\text { killed by police since } 2015\end{array}$ & $\begin{array}{l}\text { No data on police officers or non-fatal shootings; data collected but not } \\
\text { available on police officers involved; no news summaries for context }\end{array}$ \\
\hline Killedbypolice.net & Citizens killed by police & $\begin{array}{l}\text { Quantitative and } \\
\text { categorical; citizens killed } \\
\text { by police since } 2014\end{array}$ & $\begin{array}{l}\text { No data on police officers or non-fatal shootings; uses scraping for data } \\
\text { collection; lack of definition for what constitutes a police officer; some context } \\
\text { but all in the form of external links with many incomplete; questionable sources }\end{array}$ \\
\hline Fatalencounters.org & Citizens killed by police & $\begin{array}{l}\text { Crowdsourced data } \\
\text { collection on citizens killed } \\
\text { by police since } 2000 \\
\text { outcome data }\end{array}$ & $\begin{array}{l}\text { Questionable definitions of police officer; incomplete data and missing data; no } \\
\text { data on police officers or non-fatal shootings; totals differ greatly from other } \\
\text { datasets }\end{array}$ \\
\hline The Gun Violence Archive & $\begin{array}{l}\text { Wide range of gun-related } \\
\text { violence }\end{array}$ & Spreadsheets, Maps & $\begin{array}{l}\text { Data cannot be exported; maps are static and just visual points; no qualitative } \\
\text { context }\end{array}$ \\
\hline Mappingpoliceviolence.org & $\begin{array}{l}\text { Citizens killed by police, } \\
\text { especially minority citizens }\end{array}$ & $\begin{array}{l}\text { Spreadsheets, Maps, Data } \\
\text { Tables, Graphs and Charts }\end{array}$ & $\begin{array}{l}\text { Largely reproduces Washington Post Data; qualitative data is news links off- } \\
\text { site; no data on police officers shot or killed or citizens non-fatally shot }\end{array}$ \\
\hline
\end{tabular}




\section{A Balanced, Multi-Perspective, Collaborative, Primary Student Research Project}

In the spring semester of 2017, I wanted to teach and learn about officer-involved shootings in an undergraduate capstone course, leading to my review of the literature and the data. The course itself was designated by the university to measure the critical thinking ability of students through the following outcome, making such a project a natural fit:

Logical analysis and synthesis of information and ideas from multiple perspectives; critical acquisition, integration, and application of knowledge in students' intellectual, personal, professional, and community lives.

Furthermore, the course was used to measure and assess several program-level outcomes, including critical thinking and research abilities as well as working in groups through the following two outcomes:

Evaluate and analyze complex criminal justice issues, reflect, draw conclusions, infer and apply previous with new learning, in written and presentation form.

Work together in groups to create visual data, analyze data, apply knowledge and professionally present results in different medium.

I thought deeply about how the course could be structured to achieve these outcomes, what needed to be measured in the course and what information was already available to utilize toward these ends. After reviewing all of the above discussed data sources, it became clear that while each offered something, a lot was missing. No database included both perspectives-the officer and the citizen — or both fatal and non-fatal events. Many did not include any qualitative context to really discern the details of each encounter, losing the trees for the forest. The data also did not allow me to teach the topic in accordance with the literature on teaching controversial issues.

To overcome the data shortcomings as well as thinking about all the outcomes of the course and how they could be meaningfully met, I decided to have students build their own mapped database of every officer-involved shooting in the United States, starting in January 2017, to include all fatal and non-fatal encounters in which a police officer and/or citizen were shot. This approach was structured from the literature on teaching controversial topics, specifically the due process (fair discussion of issues with equal attention given to both sides) and peacekeeping (discussing issues in a non-confrontational manner) models of Payne and Gainey (2000), with the professor in the role of facilitator rather than a moderator of discussions. The project was designed to be balanced to include both sides without bias (Patenaude, 2001) and stories were a critical part of understanding the context of these incidents (Ferguson and Musheno, 2000; Harding, Fox and Mehta, 2002; Klinger, Rosenfeld, Isom \& Deckard, 2016). It was also non-directive and used a practical accommodation frame (Hand, 2013; 2008). The class would learn about the population of officer-involved shootings through their own original research (data collection and analysis) and be able to get objective perspective, in real time, while mitigating the limitations of the existing data sources. The students would also create a lasting database where every shooting was given equal importance, and, most importantly pedagogically, found through student research that exists at the top levels of Bloom's taxonomy (analysis, evaluation and creation).

After thinking about the best ways to structure this approach, I settled on using a GIS-based map to create the database. The use of GIS in teaching has been firmly established in several disciplines, including but not limited to: public affairs and public administration (Ferrandino, 2014;

Journal of the Scholarship of Teaching and Learning, Vol. 20, No. 3, December 2020. josotl.indiana.edu 
Mason, 2008; Starnes, 2008; Haque, 2001), criminal justice (Althausen \& Mieczkowski, 2001; Ferrandino, 2015), social work (Hillier, 2007; Weir \& Robinson, 1998), geography (Sinton, 2009), urban planning (Yin, 2010) and economics (Peterson, 2000). This approach permitted the data to be simultaneously created in spreadsheet and visual format while allowing the students to collaborate asynchronously in the same space. This was originally intended to run one semester as a class project.

The map itself was built using ArcGIS Desktop and Online platforms so students only needed access to the internet. The map consisted of two layers that students could edit directly. The first layer was to capture all incidents across the United States in which a police officer and/or citizen were physically shot and/or killed by gunfire by one another (we were not researching citizen on citizen violence). The layer included fields for location, city, state, officer name, officer race, status of the outcome, citizen name, citizen race, type of event and complete news report of the incident. While some fields were open entry, several (race, outcome, incident type) utilized drop down menus to standardize the options for analysis. To accommodate the different interests of students and enhance balance, the second layer was included to research any reported protests as a result of any shooting that occurred as long as at least one news outlet reported it. This layer included two fields: one was a summary of what incident was being protested and a second field which permitted a clickable hyperlink to the news story used. This permitted viewers to link directly to the news story from the map point. The two layers were designed to accommodate different interests of students and be as objective as possible relative to the incidents and their social impact.

Students were introduced to the map early in the semester (in the first class period) to overview the project, its purpose and expectations. I also made a tutorial video in case students struggled using the new technology after learning it in class. At that point, students began the arduous process of documenting every officer-involved shooting that took place in the United States as of January 1, 2017. This involved time out of class searching the internet, setting news alerts and finding incidents that met our criteria. Once found, students added the information to the map, building our database. Students were also required to copy, paste and cite the best news source they could find on the incident so we could read the qualitative context of the information in the map and make keywords searchable.

In hindsight, a few things immediately stand out. First, there were many more incidents than I initially envisioned. This led me to increase the number of map points students had to add to meet the project requirements. It also became apparent that the learning curve for both the research and the technology was steep, with many students making errors in placing points at the wrong place in the map, entering blank points, incomplete information and incidents that did not meet our criteria. Thus, I spent the first two weeks of the project heavily editing and revising the students' work, including overviewing that process in class. This reduced the errors within about two weeks' time though some persisted among the few students that were only casually participating. On the other end of the spectrum were students entering information almost every day. I also participated in the process to find incidents they were missing, with the goal of honing their approach. Students were kept busy by updating existing information, though that element of the project became the most difficult as older points became less of a focus as time passed and new incidents occurred. I had to remind myself that these students were learning not only about officer-involved shootings but how to conduct research and validate data, so errors were a frustrating yet important part of the process for professor and student alike.

The initial semester project included several assignments using the data (along with the data from the Washington Post) in assignments and discussions, including a reflective essay at the end of the semester on what they learned about officer involved shootings as a result of the project. We used the map in class to talk about individual incidents that drew the students' attention as they entered them, especially focusing on incidents that were unique in some fashion or made students think differently about officer-involved shootings or protests. When the local newspaper (the second largest

Journal of the Scholarship of Teaching and Learning, Vol. 20, No. 3, December 2020. josotl.indiana.edu 
in the state) heard of our project, they offered to host our map on their website to share with the public, allowing the students to share their work with the community and the world. The newspaper interviewed the students and ran a front-page story while posting the map on all their outlets across the nation ${ }^{1}$ (see Cross, 2017). This turned the project from one in a single course to a multi-class, multi-semester project that continued for three more semesters and involved over sixty students that eventually included another capstone course, graduate students doing independent research over the summer and a criminological theory course. Figure 1 below shows the final map created by these students with 1,799 entries between January 1, 2017 and May 1, 2018.

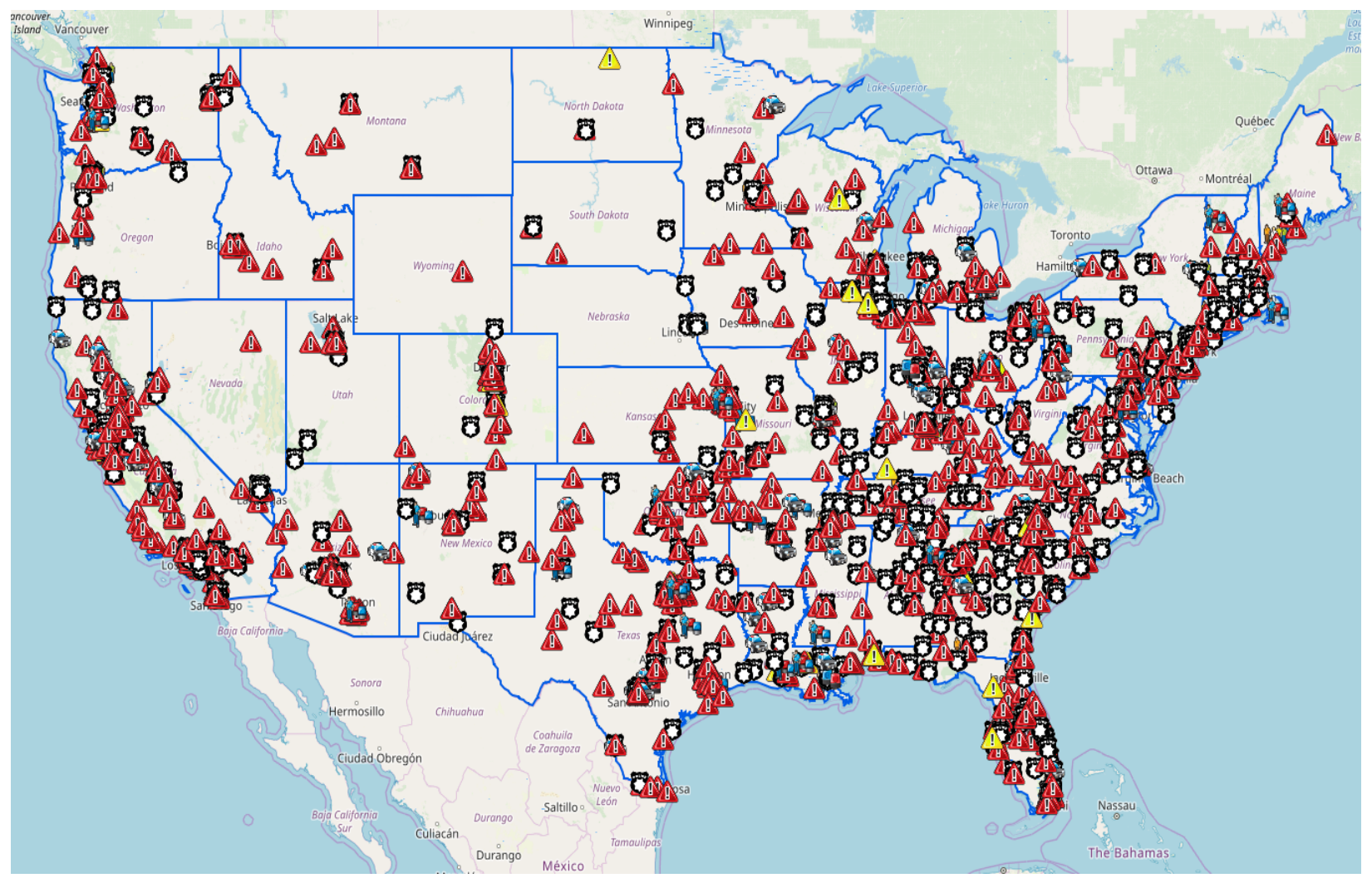

Figure 1: Final Student Map of Officer Involved Shooting Incidents. ${ }^{1}$

\section{Reflecting on the Project and the Knowledge it Produced}

This project was designed to teach students about a controversial topic objectively with the main goals of enhancing their critical and analytical thinking skills through collaboration. It was not about creating data but using the data they created to learn about the full spectrum of officer-involved shootings from both the police and citizen perspectives. Their primary research took the class discussions in many unexpected directions as we reviewed and analyzed individual incidents and any patterns that emerged. I ruminate here on what I learned about, and from, this project.

One of the major patterns that emerged was our collective surprise to learn how many of these incidents occurred in rural areas across America, and how the volume of incidents differed across

\footnotetext{
1 The application is available online at https://nwipsdc.maps.arcgis.com/apps/webappviewer/index.html?id=fbb142f17a944825af1b3266430ab841. The data can be queried, filtered, and downloaded (exported to .csv format). You can also embed this link in your LMS for any class to access.
} 
cities and states. The mapping process gave us geographical context that spreadsheets lack. Ordinarily, we hear about local officer-involved shootings or the few that rise to national prominence but would not hear about incidents throughout rural America. Thus, the map allowed us to learn about incidents we would never have heard of, expanding our limited knowledge about officer-involved shootings, who they involved and how they occurred. Two particular discussions stood out. The first was a discussion of a small-town shooting in New Carlisle, Ohio (population 5,700) where a police officer shot a local reporter setting up his tripod to take a picture in a parking lot. The students were shocked when we read the news report in class, which read:

A photojournalist in the small Ohio town of New Carlisle was allegedly shot by a police officer on Monday night after his camera and tripod was "apparently [mistaken] for a weapon.".....According to New Carlisle News, Grimm was driving along the town's Main Street when he noticed a traffic stop ahead. He said he pulled into a nearby parking lot "in full view" of the police officer on duty, intending to take photographs there. When he emerged from his vehicle and began setting up his tripod and camera, Grimm said he was shot "without warning." New Carlisle News identified the officer who shot Grimm as Deputy Jake Shaw. "I know Jake. I like Jake. I don't want him to lose his job over this," Grimm told the paper after the incident. New Carlisle has been described as a small town "where everyone knows everyone." (Mosbergen, 2017)

Contrary to other controversial shootings, the students discussed the victim liking the officer and not wanting him fired, which was out of the ordinary in our research. A follow up two years later would find the photographer suing the officer and the department. The other discussion that stood out was why there were so many shootings in Tennessee compared to other states, and how many of them occurred in rural areas under interesting circumstances. This led us to review each shooting in the state map point by point to discuss the similarities and differences to other states, including our own. Neither discussion would have happened had students not entered the points and shared their observations with the class as we pulled them up. I learned a great deal from these incidents and discussions as well.

Another theme that emerged in student-led discussions and reflections was how often concepts from other disciplines - namely sociology, psychology, public policy, political science, health and social work-seemed to apply to the study of officer-involved shootings. We had in-depth discussions of an incident in Tennessee where a mother killed her family and then refused to put the gun down when officers arrived, being fatally shot as a result. This led to a discussion on mental health and suicide by cop, a topic not often discussed in officer-involved shootings but one that emerged often in our map reviews. We talked about the number of shootings at Walmart as an example of routine activities and social interactions of a large cross-section of society, including two at Walmarts in very close proximity in Orlando, Florida. One shooting in a Navajo Indian Reservation also spurred a class discussion on the geopolitics of reservations as the student noted there were many news reports of shootings in that and nearby reservations over the years. This is not something we had ever discussed in this class in the years prior. Many discussions touched on the issues of mental health and its relation to police interactions with citizens that led to shooting incidents. The use of force was often discussed with subtlety in this context. Finally, we discussed the wide range of weapons including toy guns and knives that were involved in these shootings. Many times this led to robust discussion on gun control and how many of these shootings are not part of that debate when you look at individual incidents as we did. Having police officers in class greatly enhanced the overall discussion and gave much needed perspective.

Journal of the Scholarship of Teaching and Learning, Vol. 20, No. 3, December 2020. josotl.indiana.edu 
Another area that emerged upon reflection was a critical assessment of the media, police, laws and fellow citizens which we could not have had without students doing the research they did in the way they did it. We became frustrated with the lack of information in news reports and their failure to follow up or update stories and frequently encountered incomplete news reports, learning that not all information is immediately available and follow up is required but is hard to find. Critical analysis of news coverage was not an original aim of this project, but became a frequent topic of discussion. Many map entries remain in their original status as there was little if any follow up on the incident, and citizen information is reported far more often than those of the police officers involved, unless the officers were victims. We observed and discussed that many stories were officer-friendly rather than objective. This was a limitation of the verbatim use of news reports about officer-involved shootings as they have the potential to be biased for the police (Hirschfield \& Simon, 2010). Though we sought objectivity, it was infrequently found in the media reporting of officer involved shootings.

Students were also critical of the police in many instances. One incident in particular sparked a great discussion. Police officers in Mississippi were serving a search warrant but went to the wrong address, where a man thought someone was breaking into his home. He was legally armed, but was killed by the police. While not malicious or nefarious, students were critical of this mistake. In another incident that did involve malice, a Chicago police officer claimed to have killed a man who was attempting to rob him, when in fact it was a personal issue that resulted in the officer being charged with murder. These specific incidents were important in our goal of being critical of each incident and not having blanket perceptions about police or the public when a shooting occurs. Students were equally critical of citizens who instigated incidents that put other citizens and police officers in danger. The quotes of students in their interview with the newspaper showed this reflection (see Cross, 2017):

Student 1 said her classmates' work differs from most other online databases. National news organizations, like the Washington Post, only track fatal police shootings of civilians, while pro-police organizations typically track all deaths of officers who die in the line of duty. The IUN map goes one step further by tracking all known policeinvolved shootings in which a civilian or an officer was injured or killed in 2017 across the United States. "People have their opinions and the media gives limited information, so it's up to others to search out that information. It being in one place is very helpful for everyone to see all the correlations," Student 1 said.

Student 2, 21, said she was most surprised by the sheer volume of shootings. Students say they are learning that law enforcement are often thrust into intense situations while taking calls for a domestic disturbances sparked by family arguments, mental illness and violence in the home. "I never realized how many shootings occurred each day. They are a lot of citizens being shot by police. But when you click on the point on the map, and read the news article, you see it's the citizens' fault," Student 2 said.

"That's the interesting thing about this project. There are some instances where the officers were justified to use their actions. Some were not," Student 3 said. "And for the some that were not, they're still trying to find that story. Was this really justified? Some shootings that happened a couple of months ago, they're still discussing that."

In hindsight, the main takeaway from the discussions and writings spurred by the map was that both sides are right — and wrong - about police officer involved shootings. We learned to study the trees to understand the forest, that times, though infrequent, police officers do show predatory behavior, and sometimes may lack strong judgement in their use of potentially fatal force. We also

Journal of the Scholarship of Teaching and Learning, Vol. 20, No. 3, December 2020. josotl.indiana.edu 
learned that citizens many times put officers in situations that lead to these shootings and the lack of information available on many shootings clouds the ability to draw definitive conclusions on fault. In short, the project was successful in its desired course outcomes of spurring critical thought and analysis (verbally and in writing) while working together to create and analyze visual data. However, it also taught me a great deal I did not expect to learn about the process and the data produced.

\section{My Learning from the Process and the Results}

This type of project is not without peril on the part of the professor, and I will briefly reflect the many problems faced when undertaking such an endeavor despite the overall positive impacts (i.e. learning about the process). The first issue is technological. Students will need to be shown how to use a GIS system and be clear about the data parameters while they are conducting the research. There were many errors early in the semester as students learned the software and how to find and enter information. This included errant points and other problems as students used a wide variety of devices to enter information. I spent much of the early time on the project doing intensive editing and moderating. This persisted longer for a few students who delayed in becoming engaged or only sporadically participated. The positive side to this problem was that it assisted in the discussions about conducting research and data validation. Furthermore, the mistakes made me read all the map points and I learned a great deal about the context of these shootings through this process.

One error I made was in the map construction before the data collection started. I thought I had covered all the possible types of scenarios in the type category but found out later I had not. Nonfatal shootings could not be differentiated as to who the shooter was, so incidents that had an officer shot or a citizen shot could not be differentiated and shared the same symbol. As there were so many events, we could not go back and retroactively correct this error. As such, advanced planning is critical for such a project. Doing this after the fact is far more time consuming than doing it at the point in which the data is entered, but it became a teaching example through my own error rather than those of the students.

Another issue is that such a project, by its nature, needs to extend over multiple semesters, including the summer. I had planned it for one semester and needed to step in and populate the information myself to keep it accurate and up to date when there were lulls during and between semesters. Thus, the issues with teaching students about the project were recurring and editing and revising the map got more difficult as the total entries grew. Failure to do so impacts the validity and accuracy of the map going forward. This issue was alleviated by the making of tutorials, using screen capture video software, that showed students how to use the map and were loaded into Canvas to be viewed as needed. I do not know of a better remedy for this issue when researching an ongoing and pervasive social phenomenon for which artificial semesters are not well suited.

While I learned a great deal about the process of teaching controversial topics through the collaborative mapping project, the main takeaway for me is that, by and large, police-officer involved shootings are not controversial. Taken incident by incident, officer-involved shootings lose their controversy compared to learning about them generally. This was something I did not expect. I will not attempt to quantify this statement, but a review of the map information largely finds police officers having to do a unique part of their job, and that is to use deadly force against citizens for a wide variety of reasons in a range of situations. This includes officers shooting citizens, with the intent to use deadly force, but stopping when the citizen was subdued and no longer a threat. There appeared many instances of restraint in the map, something not often discussed in officer-involved shootings. There was malice and mistake found across the map, but it was not as prevalent as expected. Thus, most shootings are not controversial in nature despite this being a seemingly controversial topic, which is why I structured it the way I had. The earlier student comments in their interviews seem to echo that

Journal of the Scholarship of Teaching and Learning, Vol. 20, No. 3, December 2020. josotl.indiana.edu 
sentiment. This type of observation was only made possible by exploring the population of shootings, objectively, from both perspectives for all fatal and non-fatal events.

This type of project may be more suited to learning about controversial phenomenon (police shootings, mass or spree killings, acts of domestic terrorism or political corruption, for example) than topics which are controversial conceptually, such as the case with same-sex marriage (Hand, 2013) where subjective values are more pertinent. When a shooting incident was controversial in nature (both sides could make a claim about who was in the wrong) we could explore that and have meaningful dialogue without taking a general side in the wider debate. Officers in the class had to admit at times that the officer was in the wrong and students often critical of the police perspective had to admit when citizens played a major part in their own death or shooting. Thus, while our discussions touched on many disciplines, this type of project may not be suited for all disciplines to employ, though our work could be used as a learning tool in many courses across campuses that want to learn about this particular phenomenon.

This type of teaching is time consuming and detail intensive but I contend neither I nor the students would have learned as much had we used another method or source of data. It was one continuing part of the class but we covered other material. Having taught the same course at least a dozen times prior, we had never expanded the discussions to include so many other disciplines despite specific attempts on my part to do so. We explored places we never would have and let our collaborative research lead the way there. It was, in hindsight, as fulfilling a teaching experience as I have ever had. I was also quoted in the newspaper article after reflection (see Cross, 2017), sounding very much like a student myself:

Ferrandino said though he considers the map a constant work in progress, he hopes it serves as a conversation starter. "If somebody in December had asked me about police shootings, I would have given an answer and it would have been totally wrong," Ferrandino said. "I would have given my opinion as to what I thought was happening, but I wouldn't have had all the information. To be able to look at all of these incidents, where it's occurring, what the circumstances were, and picturing it from both sides, you're a lot more informed."

\section{Conclusion}

The study of officer-involved shootings, and the data that underlie it, are often polarized and onesided, making it difficult to teach objectively and holistically about the topic. Furthermore, the context is often missing when citizens are shot and/or killed by police absent a complete and accurate national database of every incident (Alpert, 2016; Klinger, 2012; Fyfe, 2002) so having qualitative data as part of teaching this topic is critical. As stated earlier, the entire project I created needed to be rooted in balanced objectivity from both perspectives to reach the tenets of due process and peacekeeping, respecting the many diverse perspectives and experiences of students. At the onset of my preparation for this course, this topic appeared to me as controversial. Through detailed research and critical analysis, we learned that while the forest is controversial, most of the trees are not. In that light, I believe the project was successful in its aims.

The GIS technology used here was vital to the project and allowed the data to be visualized and shared with the wider world from our classroom while being worked on by multiple classes over several semesters. Though this type of teaching with technology is time consuming and fraught with potential issues, the learning for students, professors and wider audience is worth it. There are also few limits on the fields or disciplines that can use this approach of primary collaborative student research on a host of topics that have a geographic basis. As a result of this collaborative multi-class,

Journal of the Scholarship of Teaching and Learning, Vol. 20, No. 3, December 2020. josotl.indiana.edu 
multi-semester project, we now have a database of 1,799 police officer involved shootings from around the nation for a sixteen month period, and there is still a lot to learn from the student research conducted, and much more perspective to get and take from the knowledge created. Upon reflection, though I would have changed some things structurally about the process, I believe the outcomes for myself and the many students involved were worth the time it took to create and carry out this project and suggest such an undertaking for any class where such analysis is warranted.

\section{References}

Alpert, G. P. (2016), Toward a National Database of Officer-Involved Shootings. Criminology \& Public Policy, 15(1): 237-242.

Althausen, J. D., \& Mieczkowski, T. M. (2001). The merging of criminology and geography into a course on spatial crime analysis. Journal of Criminal Justice Education, 12, 367-383.

Bittner, E. (1970). The functions of the police in modern society: A review of background factors, current practices, and possible role models. US Government Printing Office: Washington, D.C.

Campbell, B.A., J. Nix \& E.R. Maguire (2017). Is the number of citizens fatally shot by police increasing in the post-Ferguson era? Crime and Delinquency. Available online at https://doi.org/10.1177/0011128716686343

Cross, L.L. (2017). IUN students mapping police-involved shootings. Northwest Indiana Times. March 27, 2017. Found online at https://www.nwitimes.com/news/local/crime-andcourts/iun-students-mapping-police-involved-shootings/article dd925316-73fe-5728-a2f84b5927fe9a78.html

Currie, M., B.S. Paris, I. Pasquetto \& J. Pierre (2016). The conundrum of police officer-involved homicides: Counter-data in Los Angeles County. Big Data and Society. July-December, 1-14.

Epley, N. (2014). Mindwise: How We Understand What Others Think, Believe, Feel, and Want. Random House: New York.

Fatal Encounters (n.d). Found online at http://www. fatalencounters.org/

FBI (1996-2015). Law Enforcement Officers Killed and Assaulted (LEOKA) Database. Found online at https://ucr.fbi.gov/leoka

Ferguson, J.L. \& M. Musheno (2000). Teaching with stories: Engaging students in critical selfreflection about policing and in/justice. Journal of Criminal Justice Education. 11,1: 149165.

Ferrandino, Joseph (2014). Incorporating GIS as an interdisciplinary pedagogical tool throughout an MPA program. Journal of Public Affairs Education. 20(4), 529 -544.

Ferrandino, Joseph (2015). Using GIS to Apply Learning throughout the Undergraduate Criminal Justice Education. Journal of Criminal Justice Education. 26(1), 74-93.

Fyfe, J.J. (2002). Too many missing cases: Holes in our knowledge about police use of force. Justice Research and Policy. 4, 87-102.

Gregory, M.R. (2014). The procedurally-directive approach to teaching controversial issues. Educational Theory. 64(6), 627-648.

Gun Violence Archive (n.d). Found online at http://www.gunviolencearchive.org/

Hand, M. (2008). What should we teach as controversial? A defense of the epistemic criterion. Educational Theory.58(2), 213-228.

Hand, M. (2013). Framing classroom discussion of same-sex marriage. Educational Theory. 63(3), 497-510.

Haque, A. (2001). GIS, public service and the issue of democratic governance. Public Administration Review, 61(3), 259-265.

Harding, D.J., C. Fox \& J.D. Mehta. (2002). Studying rare events through qualitative case

Journal of the Scholarship of Teaching and Learning, Vol. 20, No. 3, December 2020.

josotl.indiana.edu 
studies: Lessons from a study of rampage school shootings. Sociological Methods and Research. 31(2): 174-217.

Hess, D.E. (2004). Controversies about controversial issues in democratic education. PS: Political Science and Politics. 37(2): 257-261.

Hillier, A. (2007). Why social work needs mapping. Journal of Social Work Education, 43(2), 205-221.

Hirschfield, P.J. \& D. Simon (2010). Legitimating police violence: Newspaper narratives of deadly force. Theoretical Criminology. 14(2): 155-182.

Killed by Police (n.d). Found online at http://killedbypolice.net/

Klinger, D.A. (2012). On the problems and promise of research on lethal police violence: A research note. Homicide Studies, 16(1): 78-96.

Klinger, D.A., R. Rosenfeld, D. Isom \& M.J. Deckard (2016). Race, crime and the microecology of deadly force. Criminology \& Public Policy. 15(1): 193-222.

Mapping Police Violence (n.d). Found online at https://mappingpoliceviolence.org/

Mason, S. (2008). Client-oriented projects: GIS course design with the potential to service multiple constituents. Journal of Public Affairs Education. 14(2), 241-252.

Mosbergen, D. (2017). "Ohio Police Officer Accused Of Shooting News Photographer". Huffington Post, September 5, 2017. Found online at https://www.huffpost.com/entry/ohiophotographer-shot-cop-andy-grimm-new-carlisle-news n 59ae4862e4b0dfaafcf2124e

Nix, J., B.A. Campbell, E.H. Byers \& G.P. Alpert (2017). A bird's eye view of civilians killed by police in 2015: Further evidence of implicit bias. Criminology \& Public Policy. 16(1): 309-340.

Officer Down Memorial Page (n.d). Found online at https://www.odmp.org/

Patenaude, A.L. (2001). "May God have mercy on your soul!": Exploring and teaching a course on the death penalty. Journal of Criminal Justice Education. 12(2): 405-425.

Payne, B.K. \& R.R. Rainey. (2000). Developing and dealing with controversial issues in criminal justice courses. Journal of Criminal Justice Education. 11(2): 313-325.

Peterson Jr., K. D. (2000). Using a geographic economic system to teach economics. Journal of Economic Education, 31(2), 169-178.

Shane, J.M., B. Lawton \& Z. Swenson (2017). The prevalence of fatal police shootings by U.S. police, 2015-2016: Patterns and answers from a new data set. Journal of Criminal Justice. 52, 101-111.

Sinton, D. S. (2009). Roles for GIS within higher education. Journal of Geography in Higher Education, 33(S1), S7-S16.

Starnes, B. J. (2008). Applying GIS technology in public administration education. P A Times, October Education Supplement, p. 6.

Tate, J., J, Jenkins, S. Rich, J. Muyskens, K. Elliott, T. Mellnik \& A. Williams (2016). How the Washington Post is examining police shootings in the United States. Found online at https://www.washingtonpost.com/national/how-the-washington-post-is-examining-policeshootings-in-the-united-states/2016/07/07/d9c52238-43ad-11e6-8856f26de2537a9d story.html?utm term $=.83466 \mathrm{cf3} 35 \mathrm{e} 9$

US Census Bureau (2016). US Quickfacts. Found online at https://www.census.gov/quickfacts/fact/table/US/PST045216

Warnick, B.R. \& D.S. Smith (2014). The controversy over controversies: A plea for flexibility and for "soft-directive" teaching. Educational Theory. 64(3), 227-244.

Washington Post (n.d.). Police shooting database. Available online at https://www.washingtonpost.com/graphics/national/police-shootings-2017/

Journal of the Scholarship of Teaching and Learning, Vol. 20, No. 3, December 2020. josotl.indiana.edu 
Ferrandino

Weir, K., \& Robinson, J. G. (1998). Teaching geographic information systems for social work applications. Journal of Social Work Education, 34(1), 81-96.

Yin, L. (2010). Integrating 3D visualization and GIS in planning education. Journal of Geography in Higher Education, 34(3), 419-438.

Yacek, D. (2018). Thinking controversially: The psychological condition for teaching controversial issues. Journal of Philosophy of Education. 52(1), 71-86. 